\title{
El curriculum y los manuales escolares de historia y de geografía en la educación secundaria valenciana (1990-2010)
}

Rafael Valls Montés

Universitat de València

\section{Los manuales analizados y las razones de su selección}

Los manuales escolares objeto de este estudio son los de las cinco editoriales más utilizados en el ámbito escolar valenciano. Su cuota global de mercado sobrepasa el $75 \%$ y la particular de cada una de ellas está bastante igualada y oscila entre el 15 y el $18 \%$. Todas ellas son de ámbito estatal y sólo la editorial ECIR tiene radicada su sede en Valencia y sus autores son casi exclusivamente valencianos.

\section{Las características del currículo valenciano de la Educación Secundaria Obligatoria y del Bachillerato}

Antes de comenzar el análisis propiamente dicho de los manuales conviene precisar las peculiaridades establecidas por la legislación autonómica para poder conocer las posibilidades y los límites que ésta establece, siempre teniendo en cuenta que por tratarse de una Comunidad Autónoma con dos lenguas cooficiales tiene a su disposición el $45 \%$ de los contenidos mínimos programables.

\subsection{Los contenidos de la Educación Secundaria Obligatoria}

Las disposiciones generales establecidas (decreto 47/1992, de 30 de marzo, publicado en el DOGV del 6-4-92) ofrecían una amplia posibilidad para el tratamiento escolar de las cuestiones relacionadas con el ámbito valenciano. Tanto en la definición de los objetivos generales, como en el desarrollo de los contenidos y en los criterios de evaluación, la presencia de las particularidades valencianas se hacía muy patente. Los posteriores cambios introducidos en los actualmente vigentes currículos de 2007 (los de la enseñanza secundaria obligatoria: DOGV del 24-7-2007) y 2008 (los del bachillerato: DOGV del 15-7-2008) apenas han variado los apartados relacionados con los objetivos generales de ambas etapas educativas ni tampoco los criterios de evaluación, pero sí lo han hecho con los contenidos, que han pasado a ser mucho más detallados y prolijos, incluyendo, en lo que se refiere a la educación secundaria obligatoria, su división curso por curso y abandonando su contemplación conjunta como se hacía en los de 1992. Dada la casi total identidad del tratamiento realizado 
sobre los objetivos y los criterios de evaluación de ambos currículos realizaremos un análisis indistinto de los mismos.

Así ocurre, por ejemplo, en el apartado de los Objetivos Generales, en el que su punto 4 establece como objetivo "conocer y valorar las especiales características de la identidad lingüística, cultural e histórica de la Comunidad Valenciana y su relación con el resto de las comunidades del Estado Español". Otro tanto ocurre con el punto 8 en el que se señala como objetivo el "conocer la riqueza del patrimonio cultural de la Comunidad Valenciana y su significado como memoria colectiva, valorando el esfuerzo de la investigación sobre él y la difusión de su conocimiento".

Lo mismo ocurre en el apartado de los Contenidos (en este caso nos referimos a los de 1992). Tanto en el bloque tercero (sociedades y territorios) como en el cuarto (sociedades y procesos históricos) y en el quinto (las sociedades actuales) se establece como referencia fundamental la Comunidad Valenciana, junto a las otras principales escalas de referencia (España, Europa y el mundo). Estas referencias a la realidad valenciana son más detalladas y reiteradas en el caso de los aspectos geográficos (bloque 3) que en los históricos (bloque 4), aunque en estos últimos, tras enumerar las características fundamentales del estudio escolar de la historia, se precise que "los estudios concretos de estos tres apartados deben hacer referencia a la historia de España y en especial al ámbito de la Comunidad Valenciana" (punto 3). Sin embargo, a la hora de precisar los estudios que necesariamente deben de realizarse sobre distintas épocas históricas, la referencia valenciana de los mismos desaparece y es sustituida por la de España en sus diferentes concreciones: "Principales manifestaciones de estas culturas (de la antigüedad clásica) en España", "la confluencia de culturas en la España medieval", "el desarrollo de la monarquía hispánica y su proyección en América" y "transformaciones de la España contemporánea". En el bloque 5, ambos referentes aparecen equiparados: "El papel de España y de la Comunidad Valenciana en las organizaciones y conflictos internacionales" (punto 1.4). La principal variante introducida en el currículo de 2007 es la reiterada alusión, en prácticamente todos los temas abordados, tanto históricos como geográficos, a la consideración de todos ellos "con especial referencia -a veces se formula como 'de manera particular'- a la Comunidad Valenciana".

En el apartado de los Criterios de evaluación, que, en cuanto objetivos finales perseguidos por la enseñanza, deben de definir con mayor precisión los contenidos del conjunto de la enseñanza secundaria obligatoria, las particularidades del currículo valenciano son bastante similares a las anteriormente descritas. En lo que respecta a los aspectos geográficos, la descripción es bastante detallada y, de esta forma, se enumera como criterios de evaluación referidos a la realidad valenciana el "identificar y localizar sus principales rasgos físicos (clima, relieve, vegetación, aguas)... y las principales actividades humanas (explotación agraria, turismo, trazado de redes de comunicación....)" (punto 1), "identificar algunas zonas del territorio valenciano..." (punto 2), "utilizar los modelos del crecimiento demográfico y el conocimiento de la distribución de la población en la Comunidad Valenciana..." (punto 3), 
"identificar, localizar y diferenciar los principales sistemas de explotación de los recursos naturales... así como algunos problemas de nuestra agricultura" (punto 4), "localizar y caracterizar los principales espacios industriales y centros de producción de materias primas y fuentes de energía en la Comunidad Valenciana..." (punto 5), "identificar y diferenciar áreas funcionales y sociales heterogéneas en un conjunto urbano de la Comunidad Valenciana, analizando diversas coyunturas históricas" (punto 6), "localizar la jerarquía urbana y los grandes ejes de comunicación y transporte en la Comunidad Valenciana..." (punto 7).

Los aspectos históricos, como ya ocurría en el apartado de los contenidos, quedan menos detallados y se engloban en formulaciones más abiertas, que pueden ser interpretadas de manera más flexible y variada. Las referencias valencianas son las siguientes: "Identificar los aspectos básicos de los principales pueblos, sociedades y culturas correspondientes al ámbito español, situándolos cronológica y geográficamente, atendiendo especialmente a los pueblos, sociedades y culturas que se desarrollaron en el ámbito actual de la Comunidad Valenciana" (punto 13) e "identificar y analizar las principales transformaciones (demográficas, económicas, sociales, políticas e ideológicas) experimentadas por la sociedad española desde la II República hasta hoy... el análisis deberá de realizarse preferentemente a partir de estudios de la actual Comunidad Valenciana en relación al estado español y a la realidad internacional" (punto 16).

En síntesis, el currículo valenciano de la Educación Secundaria Obligatoria, en lo que concierne a las "Ciencias Sociales, Geografía e Historia", abría ya en el currículo de 1992 y sigue abriendo amplias posibilidades, más explícitas en el de 2007, al tratamiento histórico y geográfico de sus características específicas.

\subsection{Los contenidos histórico-geográficos en el bachillerato}

Si en lo referente a la Educación Secundaria Obligatoria se hizo necesario detallar los aspectos en los que la realidad valenciana se hacía presente en los currículos oficiales, en el caso del bachillerato, en todas y cada una de las materias abordadas ("Historia", "Historia del mundo contemporáneo", "Geografía" e "Historia del arte"), esta cuestión se hacía radicalmente superflua en el currículo de 1994, pues en ninguna de estas asignaturas aparecía, en ninguna ocasión, el referente valenciano en ninguno de los cuatro apartados habituales de los currículos valencianos: introducción, objetivos generales, núcleos de contenidos y criterios de evaluación (DOGV, 29-9-94).

En el caso de la "Historia", su referente casi exclusivo era la "historia contemporánea de España", que aparecía reiteradamente explicitada en la mayoría de sus apartados y puntos. Otro tanto ocurría con la "Geografía", aunque en el currículo de esta asignatura "que se ocupa del espacio geográfico español", también se hacía referencia al "espacio europeo", al de la "Unión Europea" y al de "Iberoamérica". Las dos asignaturas restantes, la Historia del mundo contemporáneo y la Historia del arte, tenían un referente teóricamente mundial, aunque en la formulación con- 
creta del currículo valenciano, como en la práctica totalidad de los distintos currículos oficiales existentes, esta referencia mundial adquiría características marcadamente europeo-occidentales más que propiamente mundiales, pero esta es una cuestión que no es objetivo específico de la presente aportación. En conclusión, por lo que se refiere al curriculum de 1994, los manuales de bachillerato utilizados mayoritariamente en los centros escolares valencianos, que coinciden con los de las editoriales analizadas para la Educación Secundaria Obligatoria, sí que siguieron al pie de la letra las instrucciones administrativas valencianas y no presentaban ninguna diferencia respecto de los usados mayoritariamente en muchas de las otras autonomías españolas.

El currículo del bachillerato establecido en 2008 (DOGV, 15-7-2008), en la misma línea de lo ocurrido con el de la enseñanza secundaria, también ha supuesto una considerable "valencianización" explícita de sus contenidos, aunque menor a la acaecida en la secundaria obligatoria. Así, por ejemplo, en la asignatura de Historia de España se cita explícitamente como objeto de estudio al Reino de Valencia (en relación con la Baja Edad Media) y al actual Estatuto de Autonomía de la Comunidad Valenciana. Algo muy semejante ocurre respecto de la asignatura Historia del Arte: en este caso, las referencias van dirigidas a la pintura gótica valenciana, a la pintura impresionista valenciana (Sorolla) y a la actual Ley Valenciana del Patrimonio, incluyendo una alusión específica, en los objetivos generales y a la hora de establecer las capacidades que los alumnos deben de adquirir, la de "conocer, disfrutar y valorar el patrimonio artístico en general, y el de la Comunidad Valenciana en particular...". La asignatura de Geografía es la más explicita de las tres consideradas (ya que en la restante asignatura, la de Historia del Mundo contemporáneo, no hay ninguna alusión a las peculiaridades valencianas). En Geografía estas referencias ya se hacen explícitas a la hora de establecer Objetivos Generales (punto 4) y se van precisando más cuando se establecen los núcleos de contenidos: "el espacio geográfico valenciano" (punto III.2.); "el problema del agua en la Comunidad Valenciana" (punto III.3.); "el sector primario, la industria y el sector terciario en la Comunidad Valenciana" (punto III.4.) o "morfología y estructura de las ciudades de la Comunidad Valenciana" (punto III.5.).

\section{Principales características de los manuales escolares analizados}

Iniciamos este apartado con una descripción de los más destacados aspectos organizativos y cuantitativos de los sumarios y los contenidos de los manuales de las cinco editoriales seleccionadas como paso previo a un análisis más profundo de los mismos.

\subsection{Los manuales de la editorial Santillana-Voramar}

Una peculiaridad de esta editorial, junto a la Vicens Vives, es la de haber repartido los contenidos de geografía e historia en los cuatro cursos de la Educación Secunda- 
ria Obligatoria, como se indica en el título de cada uno de los manuales (de las ediciones vinculadas al curriculum de 1992, lo que se ha seguido manteniendo, en los relacionados con el curriculum de 2007, sólo para los dos primeros cursos de la ESO, ya que el tercer curso se dedica íntegramente a la geografía y el cuarto a la historia). Las tres restantes editoriales optaron, ya desde 1992, por asignar el manual de tercero a la geografía, el de cuarto a la historia y los dos primeros cursos a un tratamiento, más o menos articulado, de la geografía y de la historia, tal como quedó posteriormente decretado de forma oficial desde 2007.

El manual de primer curso está dividido en dos grandes bloques. El primero dedicado a la geografía física general-mundial ("el món: grans paisatges") y el segundo destinado al estudio histórico desde la prehistoria al año mil ("Europa fins a l'any mil"). A los ocho capítulos dedicados a la geografía se añade uno específico, de menor extensión que los anteriores (ocho páginas frente a las catorce habituales de cada unidad), en el que se analizan las peculiaridades geográficas valencianas (relieve, clima e hidrografía, vegetación y espacios naturales): sobre un conjunto de 120 páginas, las dedicadas a la realidad valenciana suponen un 6,6\%. Otro tanto ocurre con los aspectos históricos de este primer manual, que también se reparten en ocho unidades: en sólo cuatro de ellas aparecen unos breves apartados, de dos páginas cada uno, en los que se trata explícitamente la historia valenciana ("la prehistòria valenciana", "la cultura ibèrica a la C. Valenciana", "la València romana" y "la València islàmica"). Sobre el conjunto de las 119 páginas de historia, las referentes a la realidad valenciana son ocho, esto es el $6,7 \%$.

El manual de segundo curso tiene la misma estructura que el anterior en cuanto a la división entre temas geográficos e históricos, ahora referidos a "el mundo: gentes y paisajes" (aspectos demográficos generales y la geografía descriptiva de los diversos continentes, con especial atención a la Europa Comunitaria) y a la historia de "Europa: del año mil a las revoluciones", pero con la variedad de que en este manual las cuestiones específicas valencianas se abordan en un único capítulo que incluye 7 páginas de geografía (demografía y geografía económica) y 8 de historia (las Germanías, la Inquisición, la expulsión de los moriscos y la Guerra de Sucesión de principios del siglo XVIII). Dado que el manual tiene 247 páginas, las 15 de contenidos valencianos suponen un 6 por ciento.

Los manuales del tercer y cuarto curso son los que presentan una estructura de contenidos más estable. Cada uno de ellos consta de 19 unidades. En el de tercero éstas se dividen en dos bloques idénticos dedicados respectivamente a la geografía (el sistema mundo) y a la historia (del Antiguo Régimen a 1914) y en el de cuarto curso todos se dedican a la historia del siglo XX y al mundo actual. En ambos manuales la realidad valenciana está presente mediante los denominados "desarrollos" que son pequeñas monografías de dos páginas en las que se trata específicamente el tema en su referente valenciano. La extensión habitual de cada unidad oscila entre las 14 y las 18 páginas. En porcentajes, la presencia de las peculiaridades valencianas es de un $12 \%$ en el manual de tercero y de un $11,3 \%$ en el de cuarto curso. 


\subsection{Los manuales de la editorial Vicens Vives}

La escasa presencia de la realidad valenciana ya detectada en los manuales de la editorial Santillana-Voramar disminuye aún más en el caso de la editorial Vicens Vives. La estructura de los cuatro manuales es muy similar a la de Santillana-Voramar por lo que podemos darla por supuesta, sin necesidad de repetirla, excepto en aquellos casos en que se aprecie diferencias notables.

El manual de primer curso se divide en dos grandes bloques asimétricos: once unidades para la geografía general y cinco para la prehistoria y la historia antigua. En el bloque geográfico, la presencia valenciana se da sólo en dos de sus unidades (la cuarta: "el medio físico de la Comunidad Valenciana" y la novena: "el problema de la agricultura valenciana", que en realidad es más bien una aproximación a la problemática general de la agricultura española y europea) y con una extensión de dos páginas en cada caso, lo que representa un 2,2\% sobre el conjunto de las 177 páginas de este primer bloque. Por lo que se refiere al bloque histórico, las páginas dedicadas a la historia valenciana son seis, lo que sobre las 83 del conjunto del bloque supone un $7,2 \%$. Los temas abordados en estas seis páginas son la prehistoria, los pueblos ibéricos y el proceso de romanización.

En el manual de segundo curso la distribución de los bloques se invierte y los temas geográficos son cinco (demografía, geografía urbana y económica, más dos unidades de geografía política dedicadas a la Unión Europea y al sistema constitucional español), mientras que los históricos son once, que abarcan desde el periodo medieval hasta el siglo XVII. En el bloque geográfico se dedican dos páginas al turismo valenciano dentro de las 83 de tal conjunto, esto es, un 2,4\%. En el bloque histórico, la presencia valenciana también es muy escasa excepto en la unidad décima ("los territorios cristianos en la Península Ibérica. Siglos XII-XV"), en la que se trata, con siete páginas de extensión, la "Reconquista del Reino de Valencia", así como sus actividades económicas y el arte gótico valenciano. Anteriormente se había dedicado dos páginas a las "tierras valencianas bajo dominio musulmán" y, posteriormente, una a las Germanías, otra a "los moriscos y mudéjares" y una última al "Humanismo y Renacimiento en España y Valencia". En conjunto, este bloque histórico dedica a las cuestiones valencianas 12 de sus 180 páginas, lo que supone un $6,6 \%$ de las mismas.

El manual de tercer curso dedica 14 de sus 19 unidades a los temas históricos comprendidos entre el Antiguo Régimen y el final de la Segunda Guerra Mundial. Los cinco restantes se ocupan de la geografía económica general. En los temas históricos la presencia valenciana es muy reducida: sólo aparece en tres ocasiones ("Valencia: de Reino a provincia -en el siglo XVIII-", "pintores valencianos del siglo XIX" y "bases de la economía valenciana-siglo XX"). Son, en conjunto, 3, 5 páginas sobre las 211 de este bloque, esto es, el 1,6\%. El bloque geográfico dedica el mismo número de páginas a la economía valenciana (agricultura, industria, comercio, transporte y turismo), pero dado que, en este caso, su extensión es de 75 páginas, el porcentaje de presencia valenciana se incrementa hasta el 4,6\%. 
El cuarto curso está dedicado al periodo posterior a la Segunda Guerra Mundial (ocho unidades) y a las "perspectivas del mundo de hoy" (10 unidades). Solo en dos de estas 18 unidades se abordan cuestiones valencianas: en la unidad ocho ("el arte del siglo XX") se dedica dos páginas a los artistas valencianos de ese siglo y en la unidad 17 ("estructura de las ciudades") se ocupa una página para estudiar la "evolución urbana de una ciudad: Valencia". Este manual tiene una extensión de 265 páginas, por lo que el porcentaje "valenciano" del contenido de las mismas es del 1,1\%.

Independientemente del comentario global, que realizaremos al finalizar la descripción de los manuales seleccionados, es totalmente obvia la escasez, casi inexistencia, de las referencias valencianas en los mismos.

\subsection{Los manuales de la editorial S.M.}

Los manuales de esta editorial, como ya anotamos, presentan una estructura diferente a la de los anteriormente analizados, especialmente en los manuales del primer y segundo curso. Esta variante consiste en introducir, en las unidades dedicadas a la historia general de España, una serie de tres a cuatro páginas en las que se aborda, a modo de ejemplificaciones, las características peculiares de cada región-autonomía, en nuestro caso de la valenciana. El resto de contenidos son, pues, idénticos para el conjunto del ámbito estatal español. Otra variante es la de abordar la historia y la geografía de forma conjuntada en los dos primeros cursos y de separarlas en los cursos tercero (geografía) y cuarto (historia).

En el manual del primer curso se incluye una primera parte de temática geográfica (geografía general física). De las ocho unidades que la componen, una de ellas, la número 8, se dedica íntegramente al estudio de la "Comunidad Valenciana: formas de aprovechamiento del medio" (16 páginas). En la unidad anterior se había destinado una página a "las huertas en Levante". Sobre un total de 137 páginas, las 17 dedicadas a las cuestiones valencianas suponen un 12,4\%. En el bloque histórico de este manual es donde se hace más patente la variante antes reseñada de yuxtaponer los ámbitos español-general y el regional-específico. Esto se hace en las unidades 12 ("la Península Ibérica. De la prehistoria a la historia") y 16 ("la Hispania romana") con un total de 8 páginas. El porcentaje de presencia valenciana, sobre las 129 páginas de este bloque, es del 6,2\%.

El manual de segundo curso presenta una estructura idéntica al del primer curso. En el bloque geográfico (con dos grandes temas dedicados a la "Población y recursos" y al "Estado, una forma de organización del espacio"), la presencia valenciana está concentrada en la unidad séptima, la última de este bloque, con una extensión de 16 páginas, lo que supone un 13,2 \% en relación con las 121 del conjunto. El bloque histórico, que aborda las épocas medieval y moderna, dedica 13 páginas a la historia valenciana. Tal cifra supone un 10,2 \% respecto de las 127 páginas de este segundo bloque de contenidos.

El manual del tercer curso, íntegramente dedicado a la geografía económica y política, dedica una de sus 16 unidades a los "aspectos del espacio geográfico de la 
Comunidad Valenciana" (unidad octava: 16 páginas) y una parte de la unidad 16 ("España y la Comunidad Valenciana, diversidad territorial y proyección internacional”: 4 páginas). Sobre las 287 páginas del manual, la extensión dedicada a la problemática valenciana supone un $6,9 \%$.

El manual de cuarto curso estudia la historia contemporánea general, desde el Antiguo Régimen hasta la actualidad. Tal como ocurría en el manual de segundo curso, la historia valenciana se yuxtapone, en hojas separadas, a la general española. En esta ocasión, las características valencianas son abordadas fundamentalmente a partir de documentos históricos de autores valencianos. De las 18 unidades del manual, la presencia valenciana se da en 7 de ellos, con un total de 14 páginas sobre las 319 del total de este libro, lo que significa un $4,4 \%$.

\subsection{Los manuales de la editorial Anaya}

Su estructura de reparto de los contenidos es muy semejante a la de la anterior editorial: aspectos geográficos e históricos en los dos primeros manuales y separación de los mismos en los de tercero y cuarto. Sus unidades didácticas son más breves en el primer ciclo (entre 12 y 16 páginas) y algo más extensas (normalmente 18 páginas) en los del segundo ciclo.

El manual de primer curso, en el bloque geográfico "España", dedica 4 de sus 12 páginas a las cuestiones valencianas (así ocurre en las unidades 6 a 12). El bloque histórico ("el tiempo histórico") es de tipo general y no tiene referentes estatales ni locales. Tomada en conjunto la extensión del manual (217 páginas), las dedicadas a aspectos valencianos suman 28 , esto es, un $12,9 \%$.

El manual de segundo curso repite prácticamente las características del anterior. El bloque geográfico, más breve que en ocasiones anteriores (50 páginas), está íntegramente dedicado a Europa. En el histórico se aborda la historia antigua y medieval y es mucho más extenso (229 páginas). En este bloque histórico se actúa de la misma manera que en el primer curso: en cada unidad relacionada con la historia de las sociedades de la Península Ibérica se incluye cuatro páginas con un referente valenciano. Así ocurre respecto de la prehistoria, de la Hispania romana, del periodo musulmán, de "las Españas medievales" (con la única excepción de que aquí se le dedican 6 páginas) y de la Baja Edad Media. El espacio dedicado a las características valencianas suma un total de 26 páginas que sobre las 279 del manual significan un 9,3 por ciento.

El manual de tercer curso sigue un esquema similar, pero en este caso se dedica habitualmente sólo dos páginas a la realidad valenciana, que en algunas ocasiones se incrementa hasta cuatro en función de que, sea en el estudio de una "técnica de trabajo" o en la realización de un "reportaje", se utilice o no un referente valenciano. El total de páginas con temáticas valencianas es de 30 que sobre las 276 del manual suponen un $10,8 \%$.

Algo similar ocurre en el manual del cuarto curso, aunque en esta ocasión el número de páginas dedicado a la historia valenciana son dos, salvo en una unidad 
(la 15: "La República y la dictadura de Franco") en que son cuatro. En total son 20 páginas que sobre las 319 del total significan un $6,2 \%$.

\subsection{Los manuales de la editorial ECIR}

Dos son las principales variantes de estos manuales respecto del conjunto de los ya analizados, todos ellos vinculados al curriculum de 1992 y que, según anotamos, modificó la distribución de las materias curriculares en 2007. En primer lugar, la separación completa de la geografía y de la historia en los manuales de cada ciclo: el primer y tercer curso se dedican íntegramente a la geografía, mientras que el segundo y el cuarto lo hacen a la historia (en segundo curso desde la prehistoria hasta la época moderna y, en cuarto, desde el Antiguo Régimen hasta la actualidad). La segunda variante consiste en destacar en sus índices, enmarcándolos con un color especial, los epígrafes dedicados a las cuestiones valencianas, habitualmente de una extensión de dos páginas.

En el primer curso, con contenidos relacionados con la geografía física, humana, económica y política, los diez apartados con referente valenciano suman 20 páginas, lo que representa un $8,1 \%$ sobre las 247 páginas del manual.

El manual de segundo curso rompe parcialmente la anterior estructura pues dedica una unidad completa de 12 páginas (la número 15: "las tierras valencianas en la Edad Media") a la historia valenciana. En total, las páginas con referente valenciano son 17 que suponen un 6,9\% sobre las 247 de este manual.

El manual de tercer curso sigue las pautas del de primero. Las páginas dedicadas a las cuestiones geográficas valencianas son 26 (incluyendo la cartografía final y las técnicas de trabajo) lo que supone un 7,2\% sobre las 359 del total del libro.

El manual del cuarto curso incluye, en cada una de sus seis unidades didácticas, un breve apartado de la historia valenciana contemporánea. Estas páginas suman un total de 20 sobre las 349 del manual y suponen, por tanto, un 5,7\% de su conjunto.

\section{La presencia cuantitativa de las peculiaridades valencianas en los manuales de la Educación Secundaria Obligatoria: un análisis contrastado}

Antes de realizar este comentario conviene que agrupemos, en una visión sintética, los datos obtenidos en el anterior análisis, tal como se reflejan en la tabla siguiente, en la que, por cuestiones de mayor legibilidad, hemos aunado los porcentajes de aquellos manuales que presentaban un doble bloque de geografía y de historia. Los resultados globales, en porcentajes, son estos: 


\begin{tabular}{|c|c|c|c|c|}
\hline Curso & primero & segundo & tercero & cuarto \\
\hline Santillana & 6,7 & 6 & 12 & 11,3 \\
\hline Vicens Vives & 4,7 & 4,5 & 3,1 & 1,1 \\
\hline S.M. & 9,3 & 11,7 & 6,9 & 4,4 \\
\hline Anaya & 12,9 & 9,3 & 10,8 & 6,2 \\
\hline ECIR & 8,1 & 6,9 & 7,2 & 5,7 \\
\hline Media por curso & 8,34 & 7,68 & 5,80 & 5,74 \\
\hline
\end{tabular}

Tabla 1. La presencia cuantitativa de las peculiaridades valencianas en los manuales.

De los 20 manuales analizados, sólo tres superan, y muy escasamente, el diez por ciento en su atención a las características específicas de la geografía y de la historia valencianas. Si comparamos estos porcentajes con las recomendaciones administrativas anteriormente estudiadas, se concluye que éstas no han sido seguidas de manera adecuada por los autores de los manuales y que lejos, lejísimos, de un tratamiento "localista" de estas materias nos encontramos con una atención muy insuficiente de las mismas, pues se reduce, en términos de media, a la cifra del 6, 89 por ciento del conjunto de los contenidos estudiados. Esta situación es la que se daba en los manuales vinculados al curriculum de 1992 y es la que persiste dándose en los relacionados con el curriculum de 2007, sin apenas ninguna variación.

Estas cifras toman aún mayor relevancia si las comparamos con las obtenidas, en un anterior estudio nuestro sobre estos mismos manuales, aunque éste sólo tome en consideración los temas históricos ${ }^{1}$ (tabla 2):

1. Rafael Valls: "Tendencias actuales en los manuales españoles de historia de la Educación Secundaria Obligatoria" en F. Pingel, ed. (2001): La enseñanza de la historia en Europa. Braunschwweig, GeorgEckert-Institut (en prensa). En un estudio anterior, realizado sobre los manuales de Ciencias Sociales del ciclo superior de la extinta Educación General Básica, los porcentajes eran bastante similares (Véase R. Valls (1994): "La imagen de Europa en los actuales manuales escolares españoles de Ciencias Sociales" en Didáctica de las Ciencias Experimentales y Sociales, nº 8, pp.3-26). 


\begin{tabular}{|l|c|c|c|c|c|}
\hline \multicolumn{1}{|c|}{ Editorial } & $\begin{array}{c}\text { Resto } \\
\text { del mundo }\end{array}$ & $\begin{array}{c}\text { Europa } \\
\text { general }\end{array}$ & $\begin{array}{c}\text { Países } \\
\text { europeos } \\
\text { concretos }\end{array}$ & $\begin{array}{c}\text { Este y } \\
\text { Sureste } \\
\text { europeos }\end{array}$ & España \\
\hline Santillana & 11,3 & $35^{\prime} 2$ & 19,5 & 5,2 & 27,8 \\
\hline ECIR & 16,7 & 41,7 & 10,8 & 8,3 & 22,5 \\
\hline S.M. & 10 & 41,3 & 10,6 & 5,6 & 32,5 \\
\hline Vicens- Vives & 16,6 & 44,4 & 14,8 & 5,6 & 18,6 \\
\hline Anaya & 11,2 & 38,8 & 7,2 & 3,8 & 38 \\
\hline
\end{tabular}

Tabla 2. La presencia de las zona y países en los manuales de ESO valencianos.

El dato que más nos interesa destacar de esta segunda tabla es el referido a España, dado que en el estudio anteriormente realizado se incluyó como España el conjunto de referencias regionales-autómicas que aparecen en los mismos (el resto de porcentajes se dedicaba a analizar la "dimensión europea" y extra-europea en tales manuales, con una atención especial a los países del Este y Sureste europeos).

Dado que el porcentaje medio de presencia valenciana en estos manuales es, como ya dijimos, inferior al siete por ciento, resulta obvio, contrastando ambas tablas, que en la casi totalidad de los casos, con la excepción de la editorial Vicens Vives, las características específicas valencianas apenas ocupan entre una cuarta y una sexta parte del espacio dedicado a las del conjunto del ámbito español y que estas últimas cifras quedan muy lejos del porcentaje legalmente establecido para las primeras que, como es sabido, es el del $45 \%$.

\section{La administración educativa valenciana y los manuales escolares.}

Es suficientemente conocido que la actual administración educativa valenciana, marcadamente conservadora y que define su valencianía principalmente a través de un reiterado anticatalanismo, practica una política abiertamente excluyente respecto de algunas cuestiones que afectan al conjunto de las materias escolares y especialmente a los manuales de historia. Esta administración niega la homologación a aquellos manuales que "no se ajustan a la variedad lingüística propia de la Comunidad Valenciana y por tanto no podrá ser aprobado en esta Comunidad Autónoma" (texto literal de una resolución de junio del año 2000 en la que, como se ha venido haciendo en los últimos años, se aprobaba la versión en castellano de dos manuales de las disciplinas que estamos analizando y se rechazaba su versión valenciana).

Como es también sabido, los manuales que deseen ser homologados por la administración valenciana no pueden usar la denominación de "País Valencià" o "País 
Valenciano" ni la de "català" o catalán para denominar la lengua cooficial en estas tierras. Igualmente existe un largo listado de palabras que, en su opinión, no deben ser utilizadas por su presuntamente marcado carácter catalanista. Aparte del carácter declaradamente anticientífico y antidemocrático de tal actuación, el problema principal reside en la interiorización de tal censura por parte de los editores y de los autores de los manuales escolares que se ven constreñidos a tener que cumplir tal normativa $\mathrm{o}$, en su defecto, tener que renunciar a la homologación de sus manuales y al importante perjuicio económico y profesional que tal opción les comportará, pues los centros escolares son reacios a utilizar manuales no homologados.

Esta práctica censoria origina, en los manuales escolares, situaciones que unas veces, aunque sean poco frecuentes, son directamente anticientíficas y otras francamente malabaristas o rocambolescas. Un ejemplo de las primeras aparece en el manual de segundo curso de la editorial Anaya en que al tratar sobre las lenguas europeas, y dentro de ellas de las latinas, se enumera las siguientes: "castellano, catalán, gallego, valenciano, bable, portugués, francés, italiano, rumano, etc." (página 26, segundo párrafo).

Un ejemplo de las segundas y de los complicados juegos que realizan los autores de los manuales para sortear la censura de la administración sin adoptar posiciones anticientíficas, pero que sí podrían ser consideradas ocultadoras, como mínimo, es el ofrecido por la editorial ECIR en el manual de segundo curso. Se trata de la unidad número 15 que, como se hace constar en el índice, es una unidad "en su totalidad propia del temario de la Comunidad Valenciana" (página 7). Esta unidad trata sobre "las tierras valencianas en la Edad Media". En su apartados 5 y 6, a la hora de abordar "la tolerancia e intolerancia en la Valencia cristiana medieval" y "el arte y la cultura valenciana en la Edad Media", respectivamente, se nos informa, de forma reiterada, de que los mudéjares conservaron "su lengua (el árabe)" y de que los judíos hicieron lo mismo con la suya, además de tener "dominio de la lengua árabe" (páginas 206 y 207). Sin embargo, nos quedamos sin saber qué lengua tenían los que impulsaron la "conquista y repoblación cristiana del reino de Valencia que supuso también un profundo cambio cultural y artístico" (página 208). Las únicas pistas proporcionadas son las de que "Antoni Canals fue el primer escritor en designar como valenciano a la lengua materna... Ausiàs March fue una de las máximas figuras de la literatura europea y Joanot Martorell, autor de Tirant Lo Blanc, una de las obras que ha alcanzado mayor difusión internacional..." (página 208).

Esta situación persiste actualmente a pesar de las denuncias realizadas por editores y autores de los manuales, de los sindicatos docentes y de la propia Universitat de València que, como es sabido, tuvo que ser amparada por el Tribunal Constitucional para poder usar, en su propio ámbito de competencias, aquellas denominaciones que para la romanística científica internacional son una evidencia. 


\section{Conclusiones}

Aunque las principales conclusiones de este estudio ya aparecen bastante detalladas a lo largo de los anteriores apartados, vamos a resumirlas brevemente:

1.- El tratamiento de las cuestiones valencianas es muy inferior a las posibilidades ofrecidas por la legislación vigente. Es, por tanto, improcedente y falso completamente el afirmar que en los manuales analizados exista un exceso de "localismo". Como se ha comprobado, los referentes priorizados son el Estado español y la Europa occidental.

2.- Los manuales no adolecen de "pedagogismo" si con este concepto se quiere afirmar que tienen un exceso de enfoque didáctico en el tratamiento de sus contenidos. Por el contrario, siguen predominando los contenidos temáticos tradicionales sin haberse logrado una adecuada actualización didáctica de los mismos. Sigue predominando un concepto de la enseñanza más expositivo que activo, esto es, se privilegia la transmisión y memorización de los contenidos más que su aprendizaje real y activo por parte de los alumnos.

3.- Desde esta perspectiva, el principal problema de los manuales no es el de que falten contenidos temáticos, pues posiblemente sobran ya que la cantidad de contenidos temáticos impide su estudio en profundidad y el tratamiento razonado de los mismos. En todo caso habría que ampliar la presencia de los contenidos metodológico-procedimentales y también los actitudinales si se desea cumplir con lo estipulado por la legislación vigente (una formación cívica crítica a partir de la generación de un juicio crítico y razonado, tal como se expresa en los Objetivos Generales del curriculum valenciano de Ciencias Sociales, Geografía e Historia, tanto en los de 1992-1994 como en los de 2007-2008).

4.- El planteamiento predominante, por lo que se refiere a los contenidos "valencianos", es el que se suele definir como regionalista, esto es, el que reivindica ciertas peculiaridades de este territorio, y de las sociedades que lo han habitado tradicionalmente, dentro del conjunto territorial y social definido como España, el Estado español o la nación española (como se manifiesta en la letra del propio himno regional, creado a principios del siglo XX: "Para ofrecer nuevas glorias a España, todos a una voz, hermanos, venid...¡Paso a la Región que avanza con marcha triunfal!". No hay ningún dato, afirmación, ni siquiera amago, tanto en los currículos como en los manuales escolares, que reivindique una especificidad nacional propia para estas tierras ni las sociedades que las han habitado. El dato identificador más destacado, muy connotado políticamente en los últimos treinta años por parte de las opciones reaccionarias y conservadoras, aparece por vía negativa en el sentido de afirmar unas peculiaridades distintas y contrapuestas a lo que podría definirse como un origen social, cultural, político y lingüístico históricamente relacionado con el ámbito catalán, a partir de la configuración medieval del Reino de Valencia dentro de la Corona de Aragón. 


\section{Anexo}

A.- Manuales de la E.S.O. analizados en esta investigación:

1:- Editorial Santillana-Voramar.

Mascaró Florit, J. ; Juan Redal, E. (dirs.) et al. (1997). Geografia i Història. Primer curs (secundaria). El món: grans paisatges. Europa fins a l'any mil. Comunitat Valenciana. València, 240 pp.

Mascaró Florit, J. (dir.) et al. (1997). Geografía e Historia. Segundo curso (secundaria). El mundo: gentes y países. Europa desde el año mil a las revoluciones. Comunidad Valenciana. València, 1997, 247 pp.

Mascaró Florit, Jaume y Juan Redal, Enric (dirs.) et al.: Geografía e Historia. Tercer curso (secundaria). El sistema mundo. Del Antiguo Régimen a 1914. Comunidad Valenciana. València, 1995, 300 pp.

Mascaró Florit, Jaume y Juan Redal, Enric (dirs.) et al.: Geografía e Historia. Cuarto curso (secundaria). El siglo XX: 1914-1989. El mundo actual. España, siglo XX. Comunidad Valenciana. València, 1995, 300 pp.

2.- Editorial Anaya.

González Gallego, I.; M. Mañero Monedo; D. SÁnchez Zurro; J. Valdeón Baruque; S. Garrido Rico, I Martínez Salas: Geografía e Historia. Priner ciclo.1. Comunidad Valenciana. Madrid, 1997, $217 \mathrm{pp}$.

González Gallego, I.; M. Mañero Monedo; D. Sánchez Zurro; J. Valdeón BaruQue; S. Garrido Rico, I Martínez Salas: Geografía e Historia. Priner ciclo.2. Comunidad Valenciana. Madrid, 1997, 279 pp.

Prats, J.; J.E. Castelló; M ${ }^{a}$ C. García; I. IzuzQuiza; Ma A. Loste; (unitats de la Comunitat Valenciana: S. Garrido; I. Martínez): Geografia. Segón cicle. C. Valenciana. Madrid, 1998, $311 \mathrm{pp}$.

Prats, J.; J.E. Castelló; Ma C. García; I. Izuzquiza; Ma A. Loste; M. PonGILUPPI; (unitats de la Comunitat Valenciana: S. Garrido; I. Martínez): Història. Segón cicle. C. Valenciana. Madrid, 1998, 319 pp.

3.- Editorial S.M.

Sánchez, J.; J. Santacana; G. Zaragoza y A. Zárate: Ciencias Sociales, geografía-historia. Secundaria 1. Comunidad Valenciana. Madrid, 2000, $271 \mathrm{pp}$.

Sánchez, J.; J. Santacana; G. Zaragoza y A. Zárate: Ciencias Sociales, geografía-historia. Secundaria 2. Comunidad Valenciana. Madrid, 2000, $271 \mathrm{pp}$.

Sánchez, J. y A. Zárate: Milenio. Geografía. Segundo ciclo. Comunidad Valenciana. Madrid, 2000, $287 \mathrm{pp}$.

Santacana, J. y G. Zaragoza: Milenio. Historia. Segundo ciclo. Comunidad Valenciana. Madrid, 1999, 319 pp. 
4.- Editorial Vicens Vives.

Pons Granja, J.; M. García Sebastián; C. Gatell Arimont; J. Roig Obiol y F. Molinero Blanco: Tiempo 1. Educación Secundaria. Primer ciclo. Primer curso. Opción B. Valencia. Barcelona, 1997, 261 pp.

M. García Sebastián; C. Gatell Arimont; M. Llorens Serrano; F. Molinero Blanco; R. Ortega Canadell; J. Pons Granja; J. Roig Obiol y C. Viver Pi-Sunyer: Tiempo 2. Educación Secundaria. Primer ciclo. Segundo curso. Opción B. Valencia. Barcelona, 1997, 269 pp.

A. Fernández; M. Llorens; F. Molinero; R. Ortega; J. Pons y J. Roig: Tiempo 3. Educación Secundaria. Segundo ciclo. Tercer curso. Opción B. Valencia. Barcelona, 1998, 289 pp.

A. Fernández; M. García; C. Gatell y J. Pons: Tiempo 4. Educación Secundaria. Segundo ciclo. Cuarto curso. Opción B. Valencia. Barcelona, 1998, 265 pp.

5.- Editorial ECIR.

Grupo Edetania (E. García Almiñana; J.P. Gomis Llorca; J. González Salcedo; F. Latorre Nuevalos; G. Ramírez Aledón y R. Sebastián Vicent: Saiti 1. Geografía. ESO. Primer ciclo. Comunidad Valenciana. Valencia, 2000, 263 pp.

Grupo Edetania (E. García Almiñana; J.P. Gomis Llorca; J. González Salcedo;

F. Latorre Nuevalos; G. Ramírez Aledón y R. Sebastián Vicent: Saiti 2. Historia. ESO. Primer ciclo. Comunidad Valenciana. Valencia, 2000, 247 pp.

Grupo Edetania (E. García Almiñana; J.P. Gomis Llorca; J. González Salcedo; F. Latorre Nuevalos; G. Ramírez Aledón y R. Sebastián Vicent): Saiti 3. Geografía. ESO. Segundo ciclo. Comunidad Valenciana. Valencia, 2000, 359 pp. Grupo Edetania (E. García Almiñana; J.P. Gomis Llorca; J. González Salcedo; F. Latorre Nuevalos; G. Ramírez Aledón y R. Sebastián Vicent): Saiti 4. Historia. ESO. Segundo ciclo. Comunidad Valenciana. Valencia, 2000, 349 pp.

B.- Manuales del Bachillerato analizados en esta investigación:.

Tusell, Javier: Historia de la España contemporánea. 2 Materia Común. Madrid, Santillana, 1996, $479 \mathrm{pp}$.

García de Cortázar, F.; J.M. Donézar; J. Valdeón y M. Fernández CuadraDO: Historia. Bachillerato Logse 2. Madrid, Anaya, 1998, 461 pp.

Grup Edetània (E. García Almiñana; J.P. Gomis Llorca; J. González Salcedo; F. Latorre Nuevalos; G. Ramírez Aledón y R. Sebastián Vicent): Història 2. Batxillerat. Valencia, Ecir editorial, 1999, 413 pp.

Santacana, J. y G. Zaragoza: Historia 2. Madrid, S.M., 1999, 447 pp.

Aróstegui, J.; M. García; C. Gatell y J. Palafox: Panorama. Historia. Barcelona, Vicens Vives, 2000, 335 pp. 